\title{
A new therapeutic regimen on prevention of Bronchopulmonary Dysplasia (BPD) in preterm infant
}

\author{
Hsin-Chun Huang ${ }^{1}$, I-Lun Chen ${ }^{1}$ and Tsu F Yeh ${ }^{2,3}$ \\ ${ }^{1}$ Division of Neonatology, Department of Pediatrics, Kaohsiung Chang Gung Memorial Hospital and College of Medicine, Chang Gung University, Taipei, Taiwan \\ ${ }^{2}$ Maternal Child Health Research Institute, Taipei Medical University, Taipei, Taiwan \\ ${ }^{3}$ Department of Pediatrics, Children's Hospital, China Medical University, Taichung, Taiwan
}

Although the advance of prematurity care and gentle ventilation have significantly improved the survival rate of very low birth weight infants, bronchopulmonary dysplasia (BPD) continuously to be the most common chronic lung disease $[1,2]$ in infancy. Several antenatal, perinatal and postnatal factors may contribute to the development of BPD [3,4]. It is postulated that early lung injury, inflammation, immaturity and arrestment of lung development play an important role in the pathogenesis of BPD [5,6]. Various strategies, including vitamin $A$ and caffeine has been shown beneficial for prevention or treatment for BPD $[7,8]$. However, none of these therapies can eliminate this complication. Postnatal corticosteroids therapies, in particular, dexamethasone has been used in infant with evolving BPD and in infant with difficult extubation. However, systemic dexamethasone therapy in premature infants is not generally recommended because of the long-term adverse neurodevelopmental outcomes $[9,10]$. Inhaled steroids refer to less complication than systemic steroids, but technically difficult and the effects are limited [11]. Our research showed that, by using surfactant as vehicle, intratracheal administration of surfactant/ budesonide compared with surfactant alone significantly decreased the incidence of BPD or death without apparent immediate and long-term side effect [12]. This new therapeutic regimen is based on a physical phenomenon "Marangoni effect" that surfactant can be used as an effective vehicle to facilitate the delivery of a topical steroid, budesonide, to the lung periphery. Budesonide will remain in the lung [13] for some time and inhibit the lung inflammation. Pharmacokinetic study showed that more than $80 \%$ of budesonide remained in the lungs for up to 8 hours after intra-tracheal instillation of surfactant/budesonide [13]. With a proper concentration ratio between budesonide and surfactant (survanta/ budesonide $\geq 50$, or curosurf/budesonide $\geq 160$ ), addition of budesonide to surfactant would not affect the biophysical and chemical stability of surfactant. Preliminary follow up study showed insignificant side effect.

Curosurf has a higher concentration of natural surfactants than that of Survanta, which exhibited a significantly higher Marangoni effect resulting in faster migration speed to the lung periphery [14]. Thus, based on this in vitro study [14], Curosurf is probably a better choice than other surfactants as a vehicle. A multicenter double-blind study is now ongoing. The preliminary result showed a decrease in incidence of BPD or BPD or death. However, we do not recommend routine therapy at the present until a long- term follow up study is complete and assure the safety of this new therapeutic regimen.

\section{Financial Support}

This study is supported in part from Chiesi Farmarceutici S.p.A. Via Palermo 26/A 43122, Parma, Italy (VAT IT01513360345)"

\section{References}

1. Su B-H, Hsieh W-S, Hsu C-H, Chang J-H, Lien R, Lin C-H (2015) Neonatal Outcomes of Extremely Preterm Infants from Taiwan: Comparison with Canada, Japan, and the USA. Pediatr Neonatol 56: 46-52. [Crossref]

2. Lui K, Lee SK, Kusuda S, Adams M, Vento M, et al. (2019) Trends in Outcomes for Neonates Born Very Preterm and Very Low Birth Weight in 11 High-Income Countries. J Pediatr 19: 31055-31058. [Crossref]

3. Jobe AH (2010) Lung maturation: the survival miracle of very low birth weight infants Pediatr Neonatol 51: 7-13. [Crossref]

4. Kalikkot Thekkeveedu R, Guaman MC, Shivanna B (2017) Bronchopulmonary dysplasia: A review of pathogenesis and pathophysiology. Respir Med 132: 170-177. [Crossref]

5. Huang H-C, Tai F-Y, Wang F-S, Liu C-A, Hsu T-Y, et al. (2005) Correlation of Augmented IL-8 Production to Premature Chronic Lung Disease: Implication of Posttranscriptional Regulation. Pediatr Res 58: 216-221. [Crossref]

6. Jobe AJ (1999) The new BPD: an arrest of lung development. Pediatr Res 46: 641-643. [Crossref]

7. Schmidt B, Roberts RS, Davis P, Doyle LW, Barrington KJ, et al. (2006) Caffeine therapy for apnea of prematurity. $N$ Engl J Med 354: 2112-221. [Crossref]

8. Darlow BA, Graham PJ, Rojas-Reyes MX (2016) Vitamin A supplementation to prevent mortality and short- and long-term morbidity in very low birth weight infants. Cochrane Database Syst Rev 8: CD000501. [Crossref]

9. Watterberg KL, American Academy of Pediatrics. Committee on Foetus and Newborn (2010) Policy statement--postnatal corticosteroids to prevent or treat bronchopulmonary dysplasia. Pediatrics 126: 800-808. [Crossref]

10. Yeh TF, Lin YJ, Huang CC, Chen YJ, Lin CH, et al. (1998) Early dexamethasone therapy in preterm infants: a follow-up study. Pediatrics 101: E7. [Crossref]

11. Shah VS, Ohlsson A, Halliday HL, Dunn M (2017) Early administration of inhaled corticosteroids for preventing chronic lung disease in very low birth weight preterm neonates. Cochrane Database Syst Rev 1: CD001969. [Crossref]

12. Yeh TF, Chen CM, Wu SY, Husan Z, Li TC, et al. (2016) Intratracheal Administration of Budesonide/Surfactant to Prevent Bronchopulmonary Dysplasia. Am J Respir Crit Care Med 193: 86-95. [Crossref]

${ }^{\star}$ Correspondence to: Tsu F Yeh, Maternal Child Health Research Institute, Taipei Medical University, 250 Wu Shin St. Taipei, Taiwan, E-mail: tfyeh@mail.ncku. edu.tw

Received: September 09, 2019; Accepted: September 26, 2019; Published: September 30, 2019 
Bui C (2019) Neuroblastoma in Vietnam: A retrospective analysis of $M Y C N$ status and clinical features to inform prognosis and improve outcome

13. Yeh TF, Lin HC, Chang CH, Wu TS, Su BH, et al. (2008) Early intratracheal instillation of budesonide using surfactant as a vehicle to prevent chronic lung disease in preterm infants: a pilot study. Pediatrics e1310-8. [Crossref]
14. Chen CM, Chang CH, Chao CH, Wang MH, Yeh TF (2019) Biophysical and chemical stability of surfactant/budesonide and the pulmonary distribution following intratracheal administration. Drug Deliv 26: 604-11. [Crossref]

Copyright: (C2019 Hsin-Chun H. This is an open-access article distributed under the terms of the Creative Commons Attribution License, which permits unrestricted use, distribution, and reproduction in any medium, provided the original author and source are credited. 